\title{
FAKTOR PENENTU KINERJA LINGKUNGAN PADA PAGUYUBAN BATIK KEBON INDAH BAYAT KLATEN YANG DIMODERASI OLEH LEAN ENVIRONMENT
}

\author{
Syska Lady Sulistyowatie ${ }^{1}$, Reza Widhar Pahlevi \\ ${ }^{1}$ Universitas Widya Dharma Klaten \\ Email: syskaladys@unwidha.ac.id \\ ${ }^{2}$ Universitas Islam Indonesia \\ $\triangle$ Email: rezawp@uii.ac.id
}

\begin{abstract}
$\overline{\text { Tujuan dari penelitian ini untuk mengetahui pengaruh transfer pengetahuan dan manajemen kualitas terhadap }}$ inovasi bisnis; pengaruh transfer pengetahuan, manajemen kualitas dan inovasi terhadap kinerja lingkungan; dan pengaruh inovasi terhadap kinerja lingkungan yang dimoderasi oleh lean environment pada Paguyuban Batik Kebon Indah Bayat Klaten, Jawa Tengah. Metode penelitian yang digunakan adalah deskriptif kuantitatif dengan memberikan kuesioner secara langsung kepada karyawan Paguyuban Kelompok Batik Kebon Indah Bayat Klaten Jawa Tengah. Teknik statistik yang digunakan untuk menganalisis data dengan menggunakan Structural Equation Modelling (SEM) AMOS. Hasil penelitian menunjukkan bahwa transfer pengetahuan berpengaruh terhadap inovasi, manajemen kualitas berpengaruh terhadap inovasi, transfer pengetahuan tidak berpengaruh terhadap kinerja lingkungan, manajemen kualitas berpengaruh terhadap kinerja lingkungan, inovasi berpengaruh terhadap kinerja lingkungan selanjutnya hasil penelitian menunjukkan bahwa lean environment berpengaruh terhadap kinerja lingkungan.
\end{abstract}

Kata kunci - Transfer Pengetahuan, Manajemen Kualitas, Lean Environment, Kinerja Lingkungan dan Inovasi

The research was aimed at determining the effect of knowledge transfer and quality management towards the business innovation; the effect of knowledge transfer, quality management and innovation towards the environmental performance; and the effect of business innovation and identify the role of moderation between lean environment and business innovation on the environmental performance of the batik association. The research method used was quantitative descriptive by administering questionnaires directly to the employees of the Kebon Indah Bayat Batik Association. Statistical techniques was used to analyze the data by using AMOS Structural Equation Modeling (SEM). The research results showed that 1) knowledge transfer influences innovation, quality management influences innovation; 2) knowledge transfer has no effect on environmental performance; 3) quality management influences environmental performance; 4) innovation influences environmental performance. Further, the results of the study indicate that lean environment influences environmental performance.

Keywords - Knowledge Transfer, Quality Management, Lean Environment, Environmental Performance and Innovation

(C) 2019 JBTI. All rights reserved

Article History : Received: 2019-10-14; Revised: 2019-10-22; Accepted: 2019-11-29

\section{PENDAHULUAN}


Kondisi persaingan pasar global saat ini menyita perhatian masyarakat serta pemerintah untuk meningkatkan kesadaran terhadap efek lingkungan dan sosial bagi perusahaan guna meningkatkan tingkat efisiensi dan meminimalisir risiko pada manusia dan lingkungan (Alonso et al, 2017). Masyarakat harus peduli terhadap dampak yang ditimbulkan dari perusahaan dalam memproduksi sebuah produk, terutama dalam dampak lingkungan. Saat ini perusahaan hanya memikirkan kepentingan keuntungan tanpa memikirkan dampak lingkungan yang ditimbulkan di masa depan.

Perkembangan zaman yang semakin maju diharapkan adanya penemuan pengetahuan yang bermanfaat untuk mengatasi dampak lingkungan yang ditimbulkan perusahaan. Menurut Zaied (2012), pemanfaatan pengetahuan yang efektif tidak hanya akan menciptakan keunggulan bersaing, tetapi juga meningkatkan kinerja organisasi. Namun, tidak menutup kemungkinan dampak negatif yang ditimbulkan perusahaan seperti limbah pabrik dapat diubah menjadi produk daur ulang yang ekonomis. Sedangkan menurut Joiner (2006) untuk meningkatkan pengelolaan pengetahuan akan kesadaran lingkungan dibutuhkan pengelolaan manajemen yang berkualitas agar dapat diaplikasikan kedalam produk yang lebih ekonomis. Pengelolaan manajemen yang berkualitas tersebut sering disebut sebagai total quality management (TQM) untuk mewujudkan budaya kualitas dalam organisasi guna mendukung pencapaian kinerja organisasi. Sedangkan hubungan antara manajemen pengetahuan dan inovasi menunjukkan hubungan komplementer antara dua bidang manajemen serta memberikan keunggulan kompetitif jangka panjang dalam rangka peningkatan kinerja lingkungan (Sulistyowatie \& Pahlevi, 2019).

Tantangan terbesar bagi organisasi adalah mensinergikan antara tingkat pengetahuan dan inovasi untuk menghasilkan produk yang peduli terhadap lingkungan dengan harga dan kualitas yang kompetitif dan berkualitas. Peran inovasi sangatlah penting agar keberlangsungan organisasi dan produk dapat bertahan serta dapat mencapai keunggulan bersaing dengan kompetitornya. Fenomena yang ada di negara maju, masyarakatnya sudah peduli dengan lingkungan sekitar melalui menggunakan barang yang bias didaur ulang dan tidak merusak lingkungan. Berdasarkan teori legitimasi, perusahaan seharusnya harus mampu berupaya menghasilkan untuk membuat aktivitas operasional dalamlingkup serta norma yang berlaku di mayarakat dilingkungan sekitar berada (Deegan, 1996). Kegiatan yang perlu diperhatikan adalah banyak perusahaan yang melaksanakan kegiatan operasionalnya hanya berfokus pada laba yang dihasilkan tanpa memperhitungkan dampak lingkungan yang disebabkan oleh kegiatan industrinya, sehingga menimbulkan konsekuensi terhadap lingkungan sekitar perusahaan.Segala aktivitas perusahaan, yang dilakukan secara langsung maupun tidak, dapat berdampak pada lingkungan yang ada disekitarnya, dan dapat menjadikan perusahaan yang mampu digunakan untuk memperhatikan lingkungan makhluk hidup di saat melakukan kegiatan operasional perusahaan.

Penggabungan pengetahuan dan manajemen kualitas dalam melakukan inovasi sudah dilakukan oleh Paguyuban Batik Kebon Indah di Bayat, Klaten, Jawa Tengah. Para pengerajin batik melakukan inovasi dengan menggunakan pewarna alami untuk mengurangi dampak lingkungan yang ditimbulkan. Bahkan warnanya tak kalah dengan pewarna buatan yang selama ini berdedar di pasaran. Tujuan dari penelitian ini adalah untuk mengetahui pengaruh transfer pengetahuan dan manajemen kualitas terhadap kinerja lingkungan melalui inovasi bisnis serta ingin mengetahui peran moderasi antara lean environment dengan inovasi bisnis terhadap kinerja lingkungan pada Paguyuban Batik Kebon Indah Bayat Klaten, Jawa Tengah

\section{KAJIAN TEORI}

Menurut Shaw et al. (2009), inovasi merupakan komponen kunci dari gagasan transfer pengetahuan. Pengetahuan adalah sumber daya strategis yang penting untuk kegiatan inovasi (Xie 
et al., 2016), sebagai hasil manajemen pengetahuan yang efektif yang dianggap sebagai metode penting untuk meningkatkan kapasitas inovasi suatu perusahaan (Donate \& Sánchez de Pablo, 2015). Oleh karena itu, kemampuan perusahaan untuk mengubah dan mengeksploitasi pengetahuan dapat menentukan tingkat inovasi, melalui penerapan metode baru untuk memecahkan masalah baru dan memenuhi permintaan pasar (Goh, 2002; Tidd et al., 2005). Chung \& Jing (2009) berpendapat bahwa perusahaan perlu mentransfer dan membagikannya dengan tujuan memperoleh pengetahuan untuk menjadi lebih inovatif.

\section{$H_{1}$. Transfer pengetahuan berpengaruh positif dan signifikan terhadap inovasi bisnis}

Perusahaan yang mengadopsi manajemen kualitas dalam sistem dan budaya mereka menunjukkan bahwa perusahaan tersebut telah mempersiapkan lingkungan yang optimal untuk inovasi (Pekovic \& Galia, 2009). Menurut Sadikoglu \& Zehir et al. (2010) menunjukkan hubungan positif antara praktik manajemen kualitas total (TQM) terhadap kinerja inovasi. Pentingnya upaya berkelanjutan untuk menerapkan praktik TQM, untuk meningkatkan kinerja inovasi.

\section{$\mathbf{H}_{2}$. Manajemen kualitas berpengaruh positif dan signifikan terhadap inovasi bisnis}

Claver et al., (2007) menyatakan bahwa penerapan kesadaran lingkungan dapat mengarah pada munculnya pengetahuan baru dalam undang-undang lingkungan dan sumber daya manusia, di tingkat operasional dan secara langsung dapat meningkatkan kinerja lingkungan. Saat ini, masalah lingkungan telah semakin meluas dan parah ketidakpastian lingkungan, yang dapat mencegah transfer pengetahuan di antara anggota perusahaan. Akibatnya, perusahaan harus menerapkan sistem manajemen lingkungan untuk mengurangi ambiguitas dan ketidakpastian lingkungan, sehingga memfasilitasi pertukaran pengetahuan yang pada akhirnya akan meningkatkan kinerja lingkungan.

\section{$\mathbf{H}_{3}$.Transfer pengetahuan berpengaruh positif dan signifikan terhadap kinerja lingkungan}

Kunci keberhasilan dalam penerapan TQM terletak pada peran sumber daya manusia dengan menciptakan pembelajaran yang berbasis pengetahuan untuk memenangkan persaingan dan meningkatkan kinerja lingkungan (Ribiere and Khorramshahgol, 2004). Beberapa peneliti menemukan adanya hubungan yang kuat antara manajemen kualitas dan transfer pengetahuan (Brachos et al, 2007). Menurut Zheng (2015), manajemen kualitas dan inovasi mempromosikan pemberdayaan karyawan, keterlibatan dan kerja tim, yang semuanya sangat terkait dengan transfer pengetahuan oleh karyawan dan berpengaruh terhadap kinerja lingkungan.

\section{H4. Manajemen kualitas berpengaruh positif dan signifikan terhadap kinerja lingkungan}

Inovasi bisnis memiliki hubungan yang positif dengan kinerja lingkungan. Inovasi melibatkan pengembangan dan implementasi ide-ide baru, perilaku, produk dan proses yang berkontribusi pada pengurangan biaya lingkungan, atau pencapaian tujuan berkelanjutan ekologis tertentu. Kinerja lingkungan yang baik dapat mendorong inovasi produk yang ramah lingkungan.

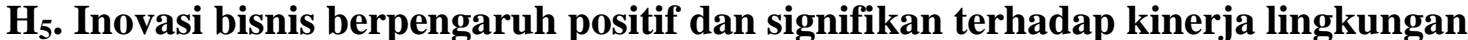

Dombrowski et al (2017) menunjukkan bahwa lean management dapat digambarkan sebagai sistem aturan aturan bagi perusahaan untuk orientasi berkelanjutan dari semua proses perusahaan yang lebih besar kepada pelanggan untuk mencapai sesuatu yang lebih besar oleh manajemen dan 
mengejar tujuan yang sistematis dan berkelanjutan seperti inovasi yang memperhatikan pengurangan aktivitas yang tidak bernilai tambah dan penyelarasan semua proses pada perspektif pelanggan serta untuk mencapai proses peningkatan berkelanjutan di seluruh perusahaan.

\section{$\mathbf{H}_{6}$. Terdapat pengaruh antara inovasi terhadap kinerja lingkungan jika dimoderasi oleh lean environement.}

\section{METODE PENELITIAN}

Data yang digunakan pada penelitian ini menggunakan data primer dan sekunder. Data primer dilakukan oleh peneliti dengan cara langsung memberikan kuesioner kepada karyawan Paguyuban Kelompok Batik Kebon Indah Bayat Klaten Jawa Tengah. Sedangkan data sekunder diperoleh secara tidak langsung melalui media perantara untuk mendapatkan dokumen pendukung berupa dokumen diterbitkan secara langsung oleh Paguyuban Kelompok Batik Kebon Indah Bayat Klaten Jawa Tengah maupun dokumen yang diterbitkan oleh pihak lain. Populasi dalam penelitian ini adalah semua kelompok dalam Batik Kebon Indah Bayat Klaten Jawa Tengah yang terdiri dari Sidoluhur, Nusa Indah, Nuju Makmur, Sido Makmur, dan Tsp Mukti. Jumlah populasi sebanyak 169 ibu-ibu yang bekerja di sektor kerajinan batik tulis dengan pewarna alam, sehingga akan digunakan secara keseluruhan dalam penelitian ini dengan teknik pengambilan data menggunakan sensus. Kuesioner dalam penelitian ini, peneliti telah menyiapkan alternatif jawaban yang dipilih oleh subjek penelitian (responden) sesuai dengan keadaan yang dialami dan dirasakan. Terhadap alternatif jawaban yang disediakan, peneliti menggunakan model yang dikembangkan oleh Likert dengan skala interval sebanyak 6 skala. Pada umumnya, skala Likert menggunakan 5 skala namun untuk menghindari jawaban yang mengambang sebagai unsur kesengajaan maka peneliti melakukan modifikasi menjadi 6 skala dengan kategori sangat tidak setuju (1), tidak setuju (2), agak tidak setuju (3), agak setuju (4), setuju (5), dan sangat setuju (6). Teknik statistik yang digunakan untuk menganalisis data dengan menggunakan Structural Equation Modelling (SEM) AMOS.

\section{HASIL DAN PEMBAHASAN}

Hasil uji validitas berdasarkan perhitungan dapat dilihat pada tabel berikut :

Tabel 1. Hasil Uji Validitas dan Reliabilitas

\begin{tabular}{|c|c|c|c|c|c|}
\hline Variable & Indikator & $\begin{array}{c}\text { Pearson } \\
\text { Correlation }\end{array}$ & Significance & Kesimpulan & $\begin{array}{l}\text { Cronbach's } \\
\text { Alpha }\end{array}$ \\
\hline \multirow{5}{*}{$\begin{array}{c}\text { Transfer } \\
\text { Pengetahuan }\end{array}$} & Item 1 & 0.378 & 0.007 & Valid & \multirow{5}{*}{0.742} \\
\hline & Item 2 & 0.668 & 0.000 & Valid & \\
\hline & Item 3 & 0.667 & 0.000 & Valid & \\
\hline & Item 4 & 0.540 & 0.000 & Valid & \\
\hline & Item 5 & 0.668 & 0.000 & Valid & \\
\hline \multirow{5}{*}{$\begin{array}{c}\text { Manajemen } \\
\text { Kualitas }\end{array}$} & Item 1 & 0.486 & 0.000 & Valid & \multirow[t]{5}{*}{0.711} \\
\hline & Item 2 & 0.768 & 0.000 & Valid & \\
\hline & Item 3 & 0.632 & 0.000 & Valid & \\
\hline & Item 4 & 0.529 & 0.000 & Valid & \\
\hline & Item 5 & 0.698 & 0.000 & Valid & \\
\hline \multirow[t]{3}{*}{ Inovasi } & Item 1 & 0.607 & 0.000 & Valid & \multirow[t]{3}{*}{0.801} \\
\hline & Item 2 & 0.672 & 0.000 & Valid & \\
\hline & Item 3 & 0.424 & 0.002 & Valid & \\
\hline
\end{tabular}




\begin{tabular}{|c|c|c|c|c|c|}
\hline Variable & Indikator & $\begin{array}{c}\text { Pearson } \\
\text { Correlation }\end{array}$ & Significance & Kesimpulan & $\begin{array}{l}\text { Cronbach's } \\
\text { Alpha }\end{array}$ \\
\hline \multirow{7}{*}{$\begin{array}{c}\text { Lean } \\
\text { Environment }\end{array}$} & Item 4 & 0.635 & 0.000 & Valid & \multirow{7}{*}{0.700} \\
\hline & Item 5 & 0.533 & 0.000 & Valid & \\
\hline & Item 1 & 0.794 & 0.000 & Valid & \\
\hline & Item 2 & 0.676 & 0.000 & Valid & \\
\hline & Item 3 & 0.892 & 0.000 & Valid & \\
\hline & Item 4 & 0.626 & 0.000 & Valid & \\
\hline & Item 5 & 0.637 & 0.001 & Valid & \\
\hline \multirow{6}{*}{$\begin{array}{c}\text { Kinerja } \\
\text { Lingkungan }\end{array}$} & Item 1 & 0.681 & 0.000 & Valid & \multirow[t]{6}{*}{0.763} \\
\hline & Item 2 & 0.674 & 0.000 & Valid & \\
\hline & Item 3 & 0.598 & 0.000 & Valid & \\
\hline & Item 4 & 0.475 & 0.016 & Valid & \\
\hline & Item 5 & 0.446 & 0.017 & Valid & \\
\hline & Item 6 & 0.577 & 0.000 & Valid & \\
\hline
\end{tabular}

*Significance at $5 \%$ level

Berdasarkan tabel di atas, nilai yang dihitung dari semua item kuesioner termasuk variabel penelitian yaitu transfer pengetahuan, manajemen kualitas, inovasi bisnis, lean environment dan kinerja lingkungan menunjukkan nilai probabilitas (sig) <0,05. Jadi kuesioner dari variabel penelitian semuanya valid, dan nilai Cronbach Alpha diperoleh dari semua hasil termasuk variabel penelitian yang menunjukkan lebih besar dari nilai 0,6. dan itu berarti dapat dihandalkan.

Selanjutnya melakukan analisis statistik deskriptif untuk menggambarkan tentang deskripsi data variabel transfer pengetahuan, manajemen kualitas, inovasi bisnis, lean environment dan kinerja lingkungan yang terdiri dari beberapa item-item pernyataan dengan skala Rendah Sekali, Rendah, Agak Rendah, Agak Tinggi, Tinggi dan Tinggi Sekali. Berikut deskripsi penilaian responden terhadap masing-masing item-item variabel penelitian yang diperoleh dengan perhitungan interval sebagai berikut :

1. Interval $>1.000 \quad \mathrm{~s} / \mathrm{d} 1.833$ kategori Rendah Sekali

2. Interval $>1.833 \mathrm{~s} / \mathrm{d} 2.667$ kategori Rendah

3. Interval $>2.667$ s/d 3.500 kategori Agak Rendah

4. Interval $>3.500$ s/d 4.333 kategori Agak Tinggi

5. Interval $>4.333 \mathrm{~s} / \mathrm{d} 5.167$ kategori Tinggi

6. Interval $>5.167 \mathrm{~s} / \mathrm{d} 6.000$ kategori Tinggi Sekali

Tabel 2. Statistik Deskriptif

\begin{tabular}{|l|l|c|c|}
\hline NO & \multicolumn{1}{|c|}{ VARIABLE } & MEAN & KATEGORI \\
\hline 1 & Transfer Pengetahuan & 5.94 & Sangat Baik \\
\hline 2 & Manajemen Kualitas & 5.82 & Sangat Baik \\
\hline 3 & Inovasi & 5.73 & Sangat Baik \\
\hline 4 & Lean Environment & 5.67 & Sangat Baik \\
\hline 5 & Kinerja Lingkungan & 5.80 & Sangat Baik \\
\hline
\end{tabular}

Berdasarkan tabel deskriptif statistik menunjukkan bahwa variabel transfer pengetahuan, manajemen kualitas, inovasi bisnis, lean environment dan kinerja lingkungan memiliki skor di kisaran > 5,167 - 6,000. Hal ini menunjukkan sudah sangat baik transfer pengetahuan yang dilakukan paguyuban, sangat baiknya sistem maanajemen kualitas, sangat baiknya inovasi bisnis, 
sangat baik tingkat lean environment dan sangat baiknya kinerja yang berbasis lingkungan. Hasil Structural Equation Model (SEM) pada persamaan struktural dapat dilihat pada gambar berikut:

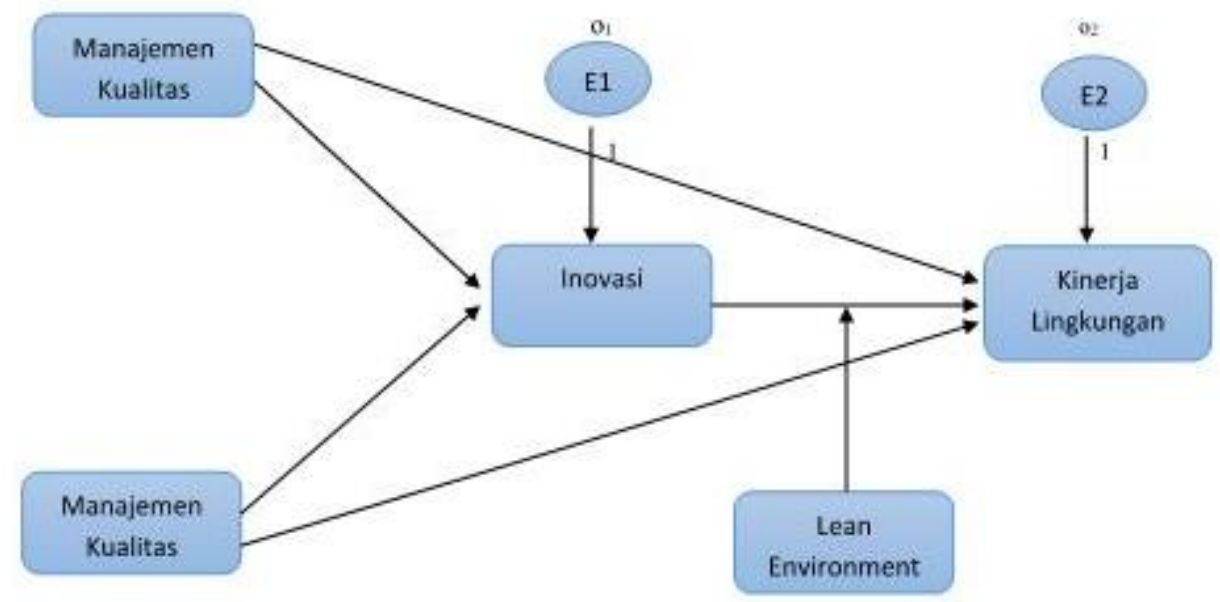

Gambar 1. Hasil Pengujian Structural Equation Model

Selanjutnya model yang telah disajikan, kemudian dinyatakan dalam persamaan-persamaan struktural dan persamaan yang menyatakan spesifikasi model pengukuran (measurement model). Pengujian model dalam Structural Equation Model dilakukan dengan dua pengujian, yaitu uji kesesuaian model dan uji signifikansi kausalitas melalui uji koefisien regresi. Pengujian model fit dengan menggunakan berbagai kriteria, yaitu Chi-square/degree of freedom (CMIN/DF), Adjusted Goodness-Of-Fit Index (AGFI), Goodness-Of-Fit Index (GFI), Comperative Fit Index (CFI), Tucker Lewis Index (TLI) dan Root Mean Square Error Approximation (RMSEA).

Tabel 3. Hasil Pengujian Kelayakan Model

\begin{tabular}{|c|c|c|c|}
\hline Kriteria & Cut of Value & Hasil & Keterangan \\
\hline Chi-Square & 37.65 & 202.677 & Baik \\
Probability & $\geq 0.05$ & 0.082 & Baik \\
CMIN/DF & $\leq 2.00$ & 1.152 & Baik \\
GFI & $\geq 0.90$ & 0.891 & Cukup Baik \\
AGFI & $\geq 0.90$ & 0.856 & Cukup Baik \\
TLI & $\geq 0.95$ & 0.984 & Baik \\
CFI & $\geq 0.95$ & 0.986 & Baik \\
RMSEA & $\leq 0.08$ & 0.032 & Baik \\
\hline
\end{tabular}

Hasil dari pengujian kelayakan model penelitian menunjukkan bahwa semua kriteria goodness of fit dapat diterima walaupun terdapat nilai marjinal pada AGFI. Nilai marjinal ini dikarenakan nilai GFI dan AGFI berada dalam rentang $0.8-0.9$ yang berarti model tersebut cukup baik. Hal tersebut juga menggambarkan bahwa hampir keseluruhan petunjuk pada model telah memenuhi nilai yang disarankan (recommended value). Dengan demikian, model akhir yang dikembangkan adalah sesuai (fit) dengan data. Secara keseluruhan model dapat diterima dan langkah selanjutnya menganalisis parameter estimate. 
Tabel 4. Hasil Pengujian Hipotesis

\begin{tabular}{|c|c|c|c|c|c|}
\hline \multicolumn{7}{|c|}{} & $\begin{array}{c}\text { Standardized } \\
\text { direct effect }\end{array}$ & C.R. & p-value & Hasil Uji \\
\hline $\begin{array}{c}\text { Transfer } \\
\text { Pengetahuan }\end{array}$ & Inovasi & 0.617 & 12.737 & 0.000 & Signifkan \\
\hline Manajemen Kualitas & Inovasi & 0.150 & 3.106 & 0.002 & Signifikan \\
\hline \multicolumn{7}{|c|}{$\mathbf{Z Y}_{\mathbf{1}}=\gamma_{\mathbf{1 . 1}} \mathbf{X}_{\mathbf{1}}+\gamma_{\mathbf{1 . 2}} \mathbf{X}_{\mathbf{2}}+\mathbf{\varepsilon}_{\mathbf{1}}$} \\
\hline $\begin{array}{c}\text { Transfer } \\
\text { Pengetahuan }\end{array}$ & Kersamaan ke-2 : $\mathbf{Z} \mathbf{Y}_{\mathbf{2}}=\gamma_{\mathbf{2 . 1}} \mathbf{Y}_{\mathbf{1}}+\boldsymbol{\gamma}_{\mathbf{2 . 2}} \mathbf{X}_{\mathbf{1}}+\boldsymbol{\gamma}_{\mathbf{2 . 3}} \mathbf{X}_{\mathbf{2}}+\mathbf{\varepsilon}_{\mathbf{2}}$ \\
\hline Manajemen Kualitas & Kinerja Lingkungan & 0.037 & 3.651 & 0.015 & Signifikan \\
\hline Inovasi & Kinerja Lingkungan & 0.337 & 4.802 & 0.000 & Signifikan \\
\hline Lean Environment & Kinerja Lingkungan & .584 & 3.216 & 0.001 & Signifikan \\
\hline
\end{tabular}

Hasil penelitian menunjukkan bahwa transfer pengetahuan berpengaruh terhadap inovasi. Menurut Shaw et al. (2009), Inovasi merupakan komponen kunci dari gagasan transfer pengetahuan. Pengetahuan adalah sumber daya strategis yang penting untuk kegiatan inovasi (Xie et al., 2016), sebagai hasil manajemen pengetahuan yang efektif yang dianggap sebagai metode penting untuk meningkatkan kapasitas inovasi suatu perusahaan (Donate \& Sánchez de Pablo, 2015). Teori sistem inovasi menekankan pentingnya pengetahuan secara umum dan transfer pengetahuan antara pihak-pihak berbeda yang terlibat dalam sistem inovasi pada khususnya, yang berarti bahwa transmisi dan penyerapan pengetahuan eksplisit dan diam-diam merupakan aspek penting dari inovasi (Wehn and Montalvo, 2018). Kegiatan transfer pengetahuan memungkinkan anggota organisasi untuk berbagi, menyebarluaskan, dan mereplikasi informasi (Donate \& Sánchez de Pablo, 2015). Oleh karena itu, kemampuan perusahaan untuk mengubah dan mengeksploitasi pengetahuan dapat menentukan tingkat inovasi, melalui penerapan metode baru untuk memecahkan masalah baru dan memenuhi permintaan pasar (Goh, 2002; Tidd et al., 2005). Chung \& Jing (2009) berpendapat bahwa perusahaan perlu mentransfer dan membagikannya dengan tujuan memperoleh pengetahuan untuk menjadi lebih inovatif. Menurut Moorman and Miner (1998), inovasi proses melibatkan akuisisi, penyebaran dan penyebaran pengetahuan baru atau yang sudah ada. Transfer pengetahuan dan aplikasinya merupakan faktor kunci keberhasilan untuk pengembangan produk baru (Kazanjian et al., 2000).

Hasil penelitian menunjukkan bahwa manajemen kualitas berpengaruh terhadap inovasi. Beberapa studi empiris telah menunjukkan bahwa manajemen kualitas secara positif terkait dengan inovasi (Abrunhosa et al., 2008 ; Martinez-Costa and Martinez-Lorente, 2008; Prajogo and Hong, 2008 ; Perdomo-Ortiz et al., 2006). Namun, hubungan antara manajemen mutu dan inovasi tidak selalu positif. Menurut Jing et al. (2015), filosofi dan prinsip manajemen mutu dianggap tidak sesuai dengan inovasi. Secara khusus, proses manajemen mutu bertujuan untuk menghilangkan semua limbah dan ketidakefisienan, dan dengan demikian dapat merusak inovasi (Sadikoglu \& Zehir, 2010). Manajemen kualitas dapat mengurangi sumber daya surplus yang sebenarnya dapat memperkaya inovasi (Sadikoglu \& Zehir., 2010). Li et al. (2018) berpendapat bahwa manajemen kualitas adalah fondasi bagi kontribusi perusahaan untuk pembangunan berkelanjutan, dan bahwa penerapannya dalam perusahaan biasanya terkait dengan inovasi yang cukup besar.

Hasil penelitian menunjukkan bahwa transfer pengetahuan tidak berpengaruh terhadap kinerja lingkungan. Beberapa penelitian yang mengkaji mengenai pengaruh antara transfer pengetahuan 
terhadap kinerja (Xie et al., 2016; Hamdoun, 2018; and Zheng, 2015). Inovasi menjembatani peran transfer pengetahuan terhadap kinerja lingkungan. Pengetahuan adalah sumber daya strategis yang penting untuk kegiatan inovasi (Xie et al., 2016). Saat ini, masalah lingkungan telah semakin meluas dan parah ketidakpastian lingkungan, yang dapat mencegah transfer pengetahuan di antara anggota perusahaan. Akibatnya, perusahaan harus menerapkan sistem manajemen lingkungan untuk mengurangi ambiguitas dan ketidakpastian lingkungan, sehingga memfasilitasi pertukaran pengetahuan yang pada akhirnya akan meningkatkan kinerja lingkungan.

Hasil penelitian menunjukkan bahwa manajemen kualitas berpengaruh terhadap kinerja lingkungan. Hubungan antara manajemen pengetahuan dan inovasi menunjukkan hubungan komplementer antara dua bidang manajemen serta memberikan keunggulan kompetitif jangka panjang dalam rangka peningkatan kinerja lingkungan. Kunci keberhasilan dalam penerapan TQM terletak pada peran sumber daya manusia dengan menciptakan pembelajaran yang berbasis pengetahuan untuk memenangkan persaingan dan meningkatkan kinerja lingkungan (Ribiere and Khorramshahgol, 2004).

Hasil penelitian menunjukkan bahwa inovasi berpengaruh terhadap kinerja lingkungan. Menurut Zheng (2015), inovasi mempromosikan pemberdayaan karyawan, keterlibatan dan kerja tim, yang semuanya sangat terkait dengan transfer pengetahuan oleh karyawan dan berpengaruh terhadap kinerja lingkungan. Teori sistem inovasi menekankan pentingnya pengetahuan secara umum dan transfer pengetahuan antara pihak-pihak berbeda yang terlibat dalam sistem inovasi pada khususnya, yang berarti bahwa transmisi dan penyerapan pengetahuan eksplisit dan diam-diam merupakan aspek penting dari inovasi (Wehn and Montalvo, 2018).

Selanjutnya hasil penelitian menunjukkan bahwa Lean Environment berpengaruh terhadap kinerja lingkungan. Dobrowski et al (2017) menunjukkan bahwa lean management dapat digambarkan sebagai sistem aturan aturan bagi perusahaan untuk orientasi berkelanjutan dari semua proses perusahaan yang lebih besar kepada pelanggan untuk mencapai sesuatu yang lebih besar oleh manajemen dan mengejar tujuan yang sistematis dan berkelanjutan seperti inovasi yang memperhatikan pengurangan aktivitas yang tidak bernilai tambah dan penyelarasan semua proses pada perspektif pelanggan serta untuk mencapai proses peningkatan berkelanjutan di seluruh perusahaan.

Perkembangan zaman yang semakin maju diharapkan adanya penemuan pengetahuan yang bermanfaat untuk mengatasi dampak lingkungan yang ditimbulkan perusahaan. Menurut Zaied (2012), pemanfaatan pengetahuan yang efektif tidak hanya akan menciptakan keunggulan bersaing, tetapi juga meningkatkan kinerja organisasi. Namun, tidak menutup kemungkinan dampak negatif yang ditimbulkan perusahaan seperti limbah dapat diubah menjadi produk daur ulang yang ekonomis. Sedangkan menurut Joiner (2006) untuk meningkatkan pengelolaan pengetahuan akan kesadaran lingkungan dibutuhkan pengelolaan manajemen yang berkualitas agar dapat diaplikasikan ke dalam produk yang lebih ekonomis. pengelolaan manajemen yang berkualitas tersebut sering disebut sebagai Total Quality Management (TQM) untuk mewujudkan budaya kualitas dalam organisasi guna mendukung pencapaian kinerja organisasi.

\section{KESIMPULAN}

Hasil penelitian menunjukkan bahwa transfer pengetahuan berpengaruh terhadap inovasi, manajemen kualitas berpengaruh terhadap inovasi, transfer pengetahuan tidak berpengaruh terhadap kinerja lingkungan, manajemen kualitas berpengaruh terhadap kinerja lingkungan, inovasi berpengaruh terhadap kinerja lingkungan selanjutnya hasil penelitian menunjukkan bahwa lean environment berpengaruh terhadap kinerja lingkungan. Menurut Zaied (2012), pemanfaatan pengetahuan yang efektif tidak hanya akan menciptakan keunggulan bersaing, tetapi juga 
meningkatkan kinerja organisasi Sedangkan menurut Joiner (2006) untuk meningkatkan pengelolaan pengetahuan akan kesadaran lingkungan dibutuhkan pengelolaan manajemen yang berkualitas agar dapat diaplikasikan ke dalam produk yang lebih ekonomis. Pengelolaan manajemen yang berkualitas tersebut sering disebut sebagai total quality management (TQM) untuk mewujudkan budaya kualitas dalam organisasi guna mendukung pencapaian kinerja organisasi. Semakin baik manajemen kualitas dan transfer pengetahuan di dalam perusahaan, maka akan menciptakan kinerja lingkungan yang baik dan berdampak pada inovasi. Saran yang biasa kami berikan untuk penelitian selanjutnya adalah sebaiknya menambah variabel lain yang sesuai dengan keadaan obyek penelitian agar hasil penelitian yang diperoleh lebih akurat.

\section{DAFTAR PUSTAKA}

Alonso. L, E.M. Rubio, B. de Agustina, R. Domingo, 2017, Latest Clean Manufacturing Trends Applied To A Worldclass Manufacturing Management For Improving Logistics And Environmental Performance. Procedia Manufacturing, vol 13, hal 1151-1158.

Brachos, D., Kostopoulos, K., Prastacos, G., Soderquist, K. E., 2007. Knowledge effectiveness, social context and innovation. Journal of Knowledge Management, vol 11(5), hal 31-44.

Chung, J.C., Jing, W.H., 2009, Strategic Human Resource Practices And Innovation PerformanceThe Mediating Role Of Knowledge Management Capacity. Journal of Business Research, vol 62(1), hal 104-114.

Claver, E., Lopez, M. D., Molina, J. F., \& Tari, J. J., 2007. Environmental Management And Firm Performance: A Case Study. Journal Of Environmental Management, vol 84, hal 606-619.

Deegan, Craig, 1996, Financial Accounting Theory. Australia: McGraw-Hill Australia Pty Limited.

Dombrowski, U., Richter, T., \& Krenkel P., 2017, Interdependencies Of Industrie 4.0 \& Lean Production Systems - A Use Cases Analysis . Procedia Manufacturing, vol 11, hal 1061 1068.

Donate, M. J., Sánchez de Pablo, J.D., 2015, The Role Of Knowledge-Oriented Leadership Inknowledge Management Practices And Innovation, Journal of Business Research, vol 68, hal 360-370.

Goh, Sunny T.H. - Khoo Kheng Hor., 2002, Marketing Wise, Jakarta: Gramedia Pustaka.

Jing, Z., Chi, A.P., \& Yoshiki, M., 2015, The Impact Of Hard And Soft Quality Management Onquality And Innovation Performance: An Empirical Study, International Journal Of Production Economics, vol 162, hal 216-226.

Joiner, T.A., 2006, Total Quality Management Dan Performance: The Role Of Organization Support And Co-Worker Support. School of Business, La Trobe University, Bundoora, Australia.

Kazanjian, R., Drazin, R. K., \& Glynn, M.A., 2000, Creativity And Technological Learning: The Roles Of Organization Architecture And Crisis In Large-Scale Projects. Journal of Engineering and Technology Management, vol 17(3/4), hal 273-298.

Pekovic, S., Galia, F., 2009, From Quality To Innovation: Evidence From Two French Employer Surveys, Technovation, vol 29, hal 829-842.

Perdomo-Ortiz, J., González-Benito, J. \& Galende, J., 2006, Total Quality Management As A Forerunner Of Business Innovation Capability, Technovation, vol 26(10), hal 1170-1185.

Sadikoglu, E., Zehir, C., 2010, Investigating The Effects Of Innovation And Employeeperformance On The Relationship Between Total Quality Management Practices And Firmperformance: 
An Empirical Study Of Turkish Firms, International Journal of Production Economics, vol 127, hal 13-26.

Sulistyowatie, S.L., dan Pahlevi, R.W., 2019, Kinerja Lingkungan Pada Paguyuban Batik Kebon Indah Di Bayat Klaten Jawa Tengah Dan Antesedennya, Prosiding, Seminar Nasional dan The 6th Call For Syariah Paper 2019. 1 (31).

Tidd, et.al., 2005, Managing Innovation Tools Value Analysis. Dalam http://www.innovationportal.info/wp-content/uploads/ValueAnalysis.pdf. Diakses pada tanggal 17 Juni 2019.

Xie, X., Fang, L., Jing, S., \& Huo, J., 2016, How Does Knowledge Inertia Affect Firms Productinnovation?, Journal Of Business Research, vol 69, hal 1615-1620.

Zaied, A. N. H., 2012, An Integrated Knowledge Management Capabilities Framework For Assessing Organizational Performance, International Journal Information Technology And Computer Science, vol 2, hal 1-10. 